\title{
Spontaneous regression of laryngeal squamous cell carcinoma: an unknown occurrence: a rare case report
}

\author{
Navneet Agarwal and Diksha Gupta*
}

\begin{abstract}
Background: Spontaneous regression of squamous cell carcinoma is extremely rare and a very challenging phenomenon. Here, we are presenting such a rare case of biopsy-proven laryngeal squamous cell carcinoma who underwent tracheostomy and later the growth regressed without any treatment.

Case presentation: A histologically proven laryngeal squamous cell carcinoma where the tumour initially leads to the tracheostomy as it compromised the airway and later on the patient presented with the accidental decannulation and the laryngoscopy showed regression of the tumour to the extent that the patient did not require retracheostomy before undergoing radiotherapy. Here, vascular insufficiency of large tumour could have necrosed the tumour along with other factors.
\end{abstract}

Conclusion: This case shows the existence of endogenous control in the host against the tumour. A greater understanding of these controlling factors may help us in the future.

Keywords: Spontaneous, Laryngeal, Carcinoma

\section{Background}

Spontaneous regression of cancer is a rare phenomenon. The published literature has very few articles on this issue. The spontaneous regression of cancer is said to occur when a malignant tumour partially or completely disappears without any treatment or in the 'presence of therapy which is considered inadequate to exert a significant influence on neoplastic disease' [1].

Boyers reported its frequency closer to 1 in 80,000 cancer cases [2].

Here, we are presenting such a rare case of biopsyproven laryngeal squamous cell carcinoma who underwent tracheostomy and later the growth regressed without any treatment.

*Correspondence: diksha06gupta@gmail.com

Department of ENT, Dr. S.N. Medical College, Hostel no: 9, Shastri Nagar, Jodhpur, Rajasthan, India

\section{Case presentation}

A 62-year-old male patient presented to our ENT outdoor with the chief complaints of change in voice since 1 year and difficulty in breathing since 10 days. There was no stridor and no complaint of dysphagia. The patient did not have any comorbidities. He was a chronic smoker.

Laryngoscopy showed a large ulceroproliferative growth on the right vocal cord extending from posterior commissure to anterior commissure involving ventricle, false and true vocal cord and fixation of the right vocal cord (T4a) (Fig. 1).

X-ray of the chest was normal. The patient refused for biopsy. He came back after 20 days with stridor. Examination showed an increase in the size of growth which was crossing the midline. Emergency tracheostomy was done to secure the airway. Laryngoscopy was done and multiple punch biopsies were taken and sent for histopathological examination which revealed it to be a welldifferentiated squamous cell carcinoma. 


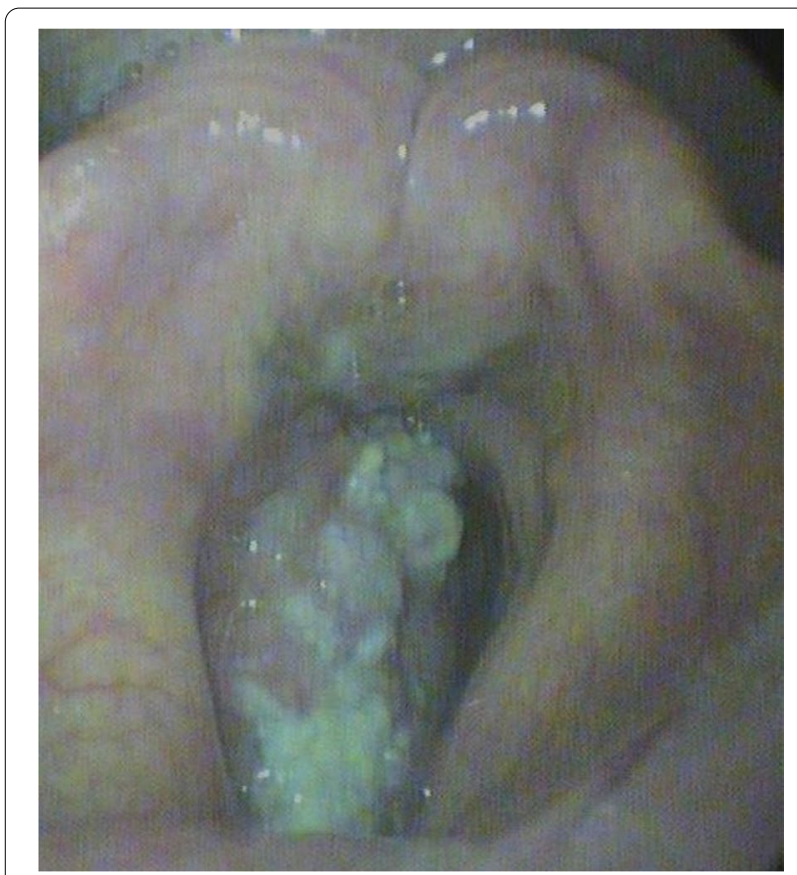

Fig. 1 Growth over the right ventricle, false and true vocal cord

The patient refused further treatment and was discharged with a tracheostomy tube in situ.

The patient came again after 4 months with accidental decannulation of the tracheostomy tube. He had not taken any type of treatment or had any episode of febrile illness or infective disease. The patient did not have any stridor. His voice had perceptibly improved. Laryngoscopy showed a perceptible decrease in size of growth which was limited to the anterior commissure and both the vocal cords were mobile (T2) (Fig. 2). The original histopathological slide was reviewed and squamous cell carcinoma was again confirmed. The growth had been regressed from T4a to T2. The patient was again counselled for radiotherapy and he received radiotherapy. $\mathrm{He}$ came again for follow-up after 2.5 years, and on laryngoscopic examination, vocal cords were mobile and no growth was seen (Fig. 3).

\section{Discussion}

In 1966, Everson and Cole studied 176 cases of spontaneous regression of cancer from 1900 to 1964 and listed criteria for the diagnosis. These are:

1. Documented histologic regression of biopsy-proven metastases

2. Radiologic regression of presumptive neoplastic disease

3. Regression of metastatic tumour following therapy deemed ineffective

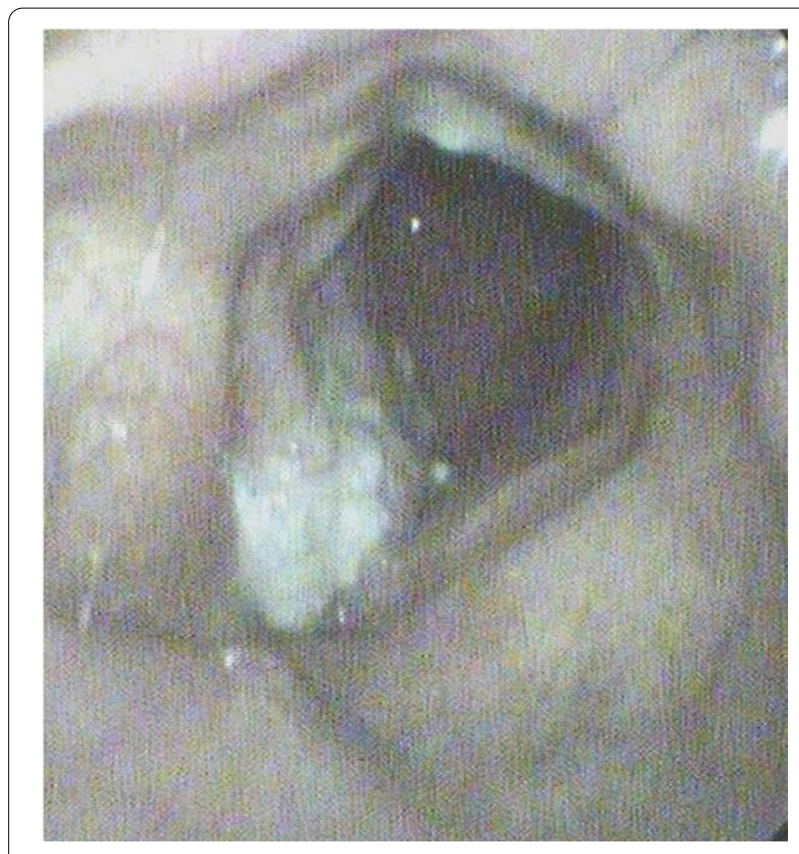

Fig. 2 Decrease in the growth over the right vocal cord

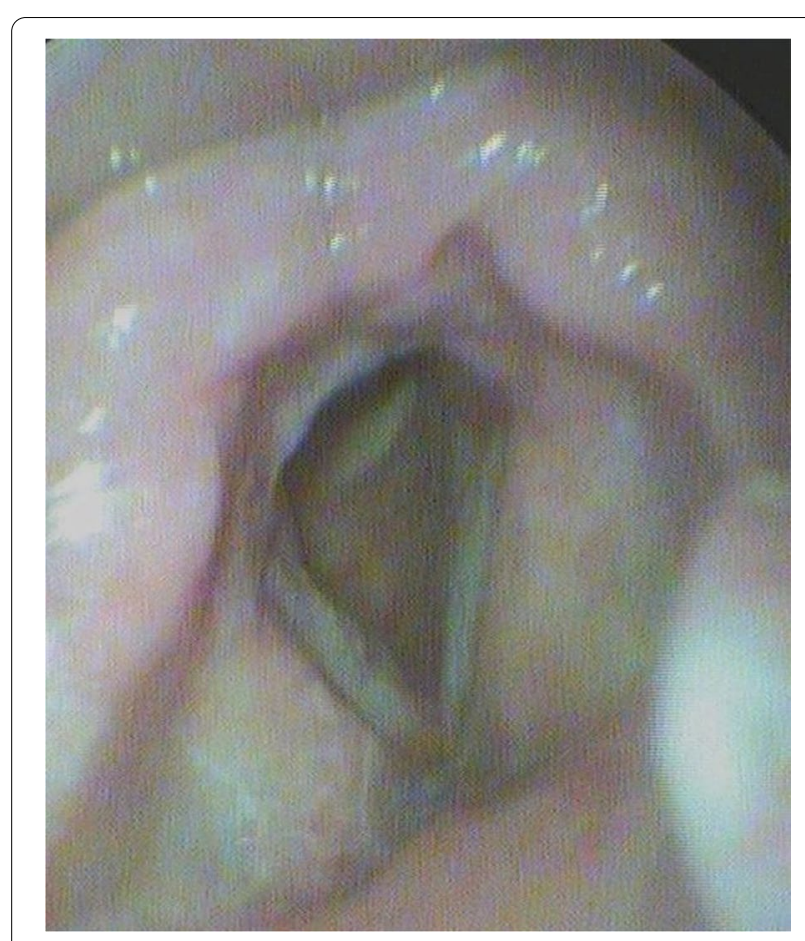

Fig. 3 Normal larynx 
Boyd suggested these spontaneously regressed tumours to be called as Saint Peregrine tumours [3].

Spontaneous regression has been commonly reported in malignant melanoma, renal cell carcinoma and neuroblastoma but rarely seen in squamous cell carcinoma (Table 1).

Mechanisms suggested by various authors to explain spontaneous regression are immunological, operative trauma, differentiation, necrosis, infection and hormonal.

Immunological factors play an important role in the spontaneous regression of tumours. Cetuximab, a monoclonal antibody which targets epidermal growth factor receptor, has been associated with prolonged survival.

Surgery reduces the burden of tumour and thus enhances the host immune system.

Necrosis stabilizes the growth of tumour by ceasing its progression by restricting the blood and nutrient supply, thus leaving the tumour to die.

In 1970, Levine reported a patient who had polypoidal growth. Stripping was done and histopathology reported as squamous cell carcinoma. The patient did not take any further treatment and was normal for the next 10 years. Here, surgery could have resulted in complete removal of the tumour as the lesion was in the T1 stage [4].

In 2015, Sipaul et al. reported a patient of glottic squamous cell carcinoma in which prolonged infection regressed the cancer [5].

We believe that this is the first case reported in literature where the size of the growth and the fixity of the vocal cord necessitated the tracheostomy. The lesion was proved on biopsy and staged as T4a. The CT of the patient also showed erosion of the cartilage. Such an extensive lesion with vocal cord paralysis regresses from T4a to T2 itself without any treatment is itself literally unheard. The regression of tumour was so significant that the patient would be decannulated prior to radiotherapy, and till date, he does not require tracheostomy. We believe that the vascular insufficiency due to the large size of tumour could have caused necrosis of the tumour along with other factors. This

Table 1 Total laryngeal cancer regression cases reported

\begin{tabular}{llll}
\hline Year & Authors & Total cases & $\begin{array}{l}\text { Laryngeal } \\
\text { cases }\end{array}$ \\
\hline $1900-1956$ & Everson and Cole & 176 & 1 \\
$1966-1987$ & Challis and Stam & 504 & 4 \\
1970 & Levine & 1 & 1 \\
2015 & Sipaul et al. & 1 & 1 \\
2018 & Vikram et al. & 1 & 1 \\
\hline
\end{tabular}

could have resulted in the release of pressure on the cricoarytenoid joint and the recurrent laryngeal nerve. Hence, the mobility of the vocal cord is restored. However, we are still not able to explain why this phenomenon occurred only in this case and not in all other patients.

\section{Conclusion}

The significance of studying spontaneous regression of cancer is that it provides evidence for the existence of endogenous control in the host against the tumour. Although initially sceptical, we strongly believe that this entity exists and it may be underreported. Shedding more light on mechanism can transform the management of malignancies in the coming future.

\section{Acknowledgements \\ Not applicable.}

\section{Authors' contributions}

NA noticed the regression and was a major contributor in writing the manuscript. DG kept the follow-up of the patient. The authors have read and approved the final manuscript and ensure that this is the case.

\section{Funding}

None.

Availability of data and materials

Not applicable.

\section{Declarations}

Ethics approval and consent to participate

Consent to participate was obtained.

\section{Consent for publication}

Written informed consent was obtained from the patient for the publication of this report and accompanying images.

\section{Competing interests}

The authors have no conflict of interest to declare.

Received: 14 May 2021 Accepted: 27 August 2021

Published online: 19 October 2021

References

1. Everson TC, Cole WH (1966) Spontaneous regression of cancer: a study and abstract of reports in the world medical literature and of personal communications concerning spontaneous regression of malignant disease. Saunders

2. Boyers LM (1953) Letter to the Editor: Queries and minor notes. JAMA 152:986

3. Boyd W (1966) The spontaneous regression of cancer. Charles C Thomas Publisher, Springfield

4. Levine MI, Reidbord HE, Busis SN (1970) Carcinoma of the larynx: a case of apparent regression after inadequate therapy. Arch Otolaryngol 91(4):385-386

5. Sipaul F, Ling B, Mason C, Keast A (2015) Spontaneous regression of laryngeal squamous cell carcinoma. J Laryngol Otol 129(12):1248-1250

\section{Publisher's Note}

Springer Nature remains neutral with regard to jurisdictional claims in published maps and institutional affiliations. 